\title{
Research and Education in Accessibility, Design, and Innovation: Integrating Post-Secondary Training in Accessibility
}

\author{
Mojtaba Ahmadi ${ }^{1}$, Adrian D. C. Chan ${ }^{1}$, Claire Davies², Lois Frankel ${ }^{1}$, Audrey Girouard ${ }^{1}$, T. C. Nicholas Graham², \\ Yvan Labiche $^{1}$, Edward Lemaire ${ }^{3}$, Jesse Stewart ${ }^{1}$, and Chantal Trudel ${ }^{1}$ \\ ${ }^{1}$ Carleton University, ${ }^{2}$ Queen's University, ${ }^{3}$ University of Ottawa
}

In Canada, approximately 1 in 7 individuals are living with a disability [1]. This segment of the population is growing, partly due to the aging population [2]. A range of barriers can prevent people from fully participating in society, especially people with disabilities; barriers may be physical or architectural, related to information, communications, and technology, attitudinal, or systemic. Accessibility refers to the design and delivery of products, facilities, and services to be independently used by people, regardless of ability.

Accessibility is important from a human rights perspective (see, e.g., the UN Convention on the Rights of Persons with Disabilities [3], Canadian Charter of Rights and Freedoms). There are legal and regulatory obligations (e.g., Accessibility for Ontarians with Disabilities Act [4]), as well as strong economic arguments for accessibility [5]. These needs and benefits results in an increased demand for accessibility expertise [5][6]. In addition, there is growing opportunity for innovation, which can establish new clusters of accessibility-focused businesses [5][6]. Despite a large and growing need for accessibility expertise, there is a shortage of engineers and designers with such training [7].

Research and Education in Accessibility, Design, and Innovation (READi; www.create-readi.ca) is a new NSERC CREATE program, whose objective is to provide professional training and skills to students to enhance their preparedness for employment in the growing number of markets defined by accessibility requirements; particularly in the areas of engineering, information and communications technology (ICT), and design. READi is an integrated, solutions-oriented training program that employs applied, experiential learning. Through active collaborations with READi partners (e.g., businesses, non-government organizations, accessibility experts, and people with disabilities), students are engaging in an interdisciplinary environment that will include a diverse number of end-users. These activities including immersive approaches such as co-designing, and other participatory research and development that focus on real-world accessibility issues. The READi program is comprised of five main elements:

1) Accessibility and Inclusive Design course: Provides foundational knowledge, exploring interdisciplinary approaches for incorporating accessible, inclusive, and human-centered design principles into the research, design, and development of products, information, and environments that can be used by all people, regardless of ability.

2) Action Team Project (ATP): An 8-month interdisciplinary project focused on real-world accessibility issues, identified by an external READi partner. Members from READi partners actively participate in the ATPs, employing co-design rather than a traditional designer-client relationship.

3) Retreat: A two-day retreat occurring mid-way through the ATP. Formal elements include an interim ATP progress report and workshops. Informal elements include social interactions between students, ATP partners, and end-users, which are important to promote affective learning.

4) Workshops: Interactive workshops for building knowledge and skills in topics, such as: web accessibility; design thinking; assistive technologies; biomedical research ethics; entrepreneurship; and accessibility in art, sport, and leisure.

5) Symposium: Involves external organizations, active in accessibility, and READi members and partners to connect and exchange information. Includes students presenting the final ATP work and a summary of the their learning journey. A keynote speaker provides a unique perspective and insight on accessibility, nationally and/or internationally.

Through this work, we: argue for the need for training in accessibility in post-secondary education, with a 
focus on engineering; share how the READi program was designed and is being delivered; and discuss how accessibility may be integrated more broadly in engineering education, including the need to support affective learning and for interdisciplinary work with other programs, including design, and those in the arts and social sciences.

[1] Statistics Canada, A profile of persons with disabilities among Canadians aged 15 years or older, Canadian Survey on Disability, 2012, Cat. No. 89-654-X, March 2015.

[2] Statistics Canada, Population Projections for Canada, (2009-2036). Cat. No. 91-520 XIE, June 2010.

[3] UN General Assembly, Convention on the Rights of Persons with Disabilities: resolution / adopted by the General Assembly, 24 January 2007, A/RES/61/106.

[4] Accessibility for Ontarians With Disabilities Act, 2005, SO 2005, c 11.

[5] Martin Prosperity Institute, Releasing Constraints: Projecting the Economic Impacts of Increased Accessibility in Ontario, June 2010.

[6] H Salah, H-D Chung, Towards an Accessible Future: Ontario Innovators in Accessibility and Universal Design, MaRS Market Insights, 2013.

[7] S Hendren, "Beyond alt-text: There's a wave of new senior corporate positions in accessible technology. But who can they hire?", Medium, 2015. available at https://medium.com/@ablerism/beyond-alt-text103b00eec89 [last accessed Jan 10, 2018]. 